\title{
HIV E AIDS, PASSADO E PRESENTE: OS GAYS COMO REPRESENTAÇÃO SOCIAL DA DOENÇA
}

\author{
Pablo de Oliveira Lopes*
}

\section{RESUMO}

Os primeiros casos brasileiros de infecção pelo HIV (da sigla em inglês, Vírus da Imunodeficiência Humana) e de AIDS (também da sigla em inglês, Síndrome da Imunodeficiência Adquirida) foram relatados em 1983. Os anos 1980 foram marcados pelo surgimento dessa infecção sexualmente transmissível, uma enfermidade que chegou a ser chamada de Doença dos $5 \mathrm{H}$, em razão de casos identificados em homossexuais, hemofílicos, haitianos, heroinômanos (usuários de heroína injetável) e prostitutas (bookers em inglês), e foi responsável pela estigmatização de gays. A própria homossexualidade já foi considerada doença: em 1952, a Associação Americana de Psiquiatria publicou, em seu primeiro Manual Diagnóstico e Estatístico de Transtornos Mentais, que a homossexualidade era uma desordem, o que levou diversos cientistas a tentar comprovar que havia um distúrbio mental nos gays. Então chamada de homossexualismo, a homossexualidade foi incluída na Classificação Internacional

* https://orcid.org/0000-0002-6779-2263. UFABC/FCMSCSP/UNINOVE.

Doutorando na área de Cultura, Comunicação e Relações de Poder do Programa de Pós-graduação em Ciências Humanas e Sociais da Universidade Federal do ABC. Mestre na área de Sociedade, Cultura e Linguagens pelo Programa de Pós-graduação Interdisciplinar em Ciências Humanas da Universidade Santo Amaro. Graduado em Medicina pela Universidade Federal do Estado do Rio de Janeiro (UNIRIO), possui estágio de especialização em Clínica Médica pelo Hospital Municipal Antônio Giglio e título de especialista em Clínica Médica pela Sociedade Brasileira de Clínica Médica e Associação Médica Brasileira (RQE - CREMESP 77120). Formado em Jornalismo na Universidade Anhembi Morumbi. Foi preceptor de alunos do curso de Medicina da Associação Fluminense de Educação (UNIGRANRIO) de outubro de 2005 a novembro de 2006. Atualmente, é preceptor do Curso de Medicina (Internato em Atenção Básica à Saude) e professor da disciplina "Práticas de cuidado, comunicação e segurança do paciente", da Faculdade de Ciências Médicas da Santa Casa de São Paulo, docente do curso de Medicina da Universidade Nove de Julho e médico internista do AC Camargo Cancer Center. Tem interesse nas áreas de Medicina (sobretudo em Clínica Médica), Educação em Saúde, Saúde Coletiva, Ciências Humanas e Sociais em Saúde, História das Ciências e da Saúde, Comunicação em Saúde, Interdisciplinaridade, Linguística (principalmente a Análise Crítica do Discurso), Jornalismo Científico, divulgação científica e Jornalismo em Saúde. Interessa-se também pelos seguintes temas: HIV/AIDS, sexualidade, gênero, identidade, televisão e telenovelas. Integrante da linha 2 do grupo de pesquisa CISGES (Ciência, Saúde, Gênero e Sentimento) da Universidade Santo Amaro (UNISA). 
de Doenças (CID) de 1977 pela Organização Mundial da Saúde (OMS). Em 1975, a Associação Americana de Psicologia deixou de considerar a orientação sexual como transtorno mental e a OMS seguiu o mesmo caminho em 1990. Apesar de não ser mais considerada uma doença, a homossexualidade ainda é associada a uma enfermidade: a AIDS. Além disso, para algumas pessoas, ser homossexual significa necessitar de cura. A sexualidade é um tema que controverso, um tabu, que desperta sentimentos e percepções distintos e é alvo de discussões em diversos segmentos da sociedade. Partindo de tais premissas, tem-se como problema de pesquisa: AIDS e homossexualidade ainda se confundem? Destarte, o objetivo desta pesquisa é mostrar se esta associação ocorre e de que maneira ela se dá. Para tanto, o presente ensaio, um estudo teórico escrito a partir de uma pesquisa exploratória, de caráter bibliográfico e documental, baseia-se em uma revisão de literatura especializada no domínio estudado, que utiliza o método de revisão narrativa, não sistemático e não exaustivo.

Palavras-chave: Homossexualidade. HIV. AIDS. Representação social.

\section{INTRODUCÃO}

A história da sexualidade, a história da ciência e a da medicina se entrelaçam em determinados momentos. Questões morais e éticas estiveram muitas vezes atreladas à sexualidade, com justificativas científicas para sustentá-las, de modo a perpetuar a produção de discursos preconceituosos. Instituições como religião, escola, família e medicina, desde o século XVIII, têm gerado tais discursos, tentando ditar formas de relacionamento sexual e afetivo. Segundo Ciasca e Pouget (2021), no século XIX, a medicina e uma de suas especialidades, a psiquiatria, criaram o conceito de "perversão sexual", definida como desvio de comportamentos tidos como "normais" por parte de uma pessoa ou um grupo de indivíduos.

A homossexualidade, por sua vez, faz parte da história da humanidade desde o princípio:

[...] e as mais conhecidas relações de philia gregas, em que era comum o coito sexual entre mestres e pupilos. Em 630 a.C., arquivos mostram que aristocratas em Creta adotavam relações entre príncipes adultos e meninos adolescentes, como o objetivo de transmitir conhecimento aos jovens. A felação e a passividade em relação ao outro homem eram determinadas de acordo com o status social, sendo o amor entre homens garantia de eficiência militar (Esparta) e liberdade cívica. (CIASCA e POUGET, 2021, p. 21). 
Foi a partir da derrocada do Império Romano e o início da Idade Média que se instaurou a perseguição a homossexuais. Conforme Ciasca e Pouget (2021), Tomás de Aquino caracterizou a sodomia (coito anal) como o segundo pior pecado, atrás apenas do assassinato. No século XIX, o termo "homossexualismo" foi criado pela medicina e os desejos homoeróticos passavam da categoria de comportamentos à de doença: "Criava-se a 'identidade homossexual'. Retira-lhe a culpa, a não ser que não deseje tratamento". (Ciasca e Pouget, 2021, p. 21).

O sufixo grego "ismo" significa doença e, portanto, atribui a homossexuais a pecha de enfermos. Por causa disso, no século XIX, homossexuais eram levados a manicômios e tratamentos para cura do "homossexualismo" foram propostos a partir do século seguinte. Já o termo "homossexualidade" indica que a orientação sexual é fruto da expressão da sexualidade e da identidade humanas.

De acordo com Ciasca e Pouget (2021), só em 1973 o "homossexualismo" foi retirado da $2^{a}$ edição do Manual diagnóstico e estatístico de transtornos mentais da Associação Psiquiátrica Americana. Em 1985, o Conselho Federal de Medicina sacou a homossexualidade da lista de doenças, decisão tomada pela Organização Mundial da Saúde (OMS) em 1990.

A despeito de ter saído do rol de doenças, a homossexualidade continuou a ser vista como uma. E isso se deu em função da epidemia do HIV/AIDS, surgida nos anos 1980, que suscitou ideias homofóbicas e discriminatórias, marcadas por estigmas que recaíram sobre gays, travestis e transexuais.

\section{HOMOSSEXUALIDADE E REPRESENTAÇÃO SOCIAL}

De que modo as informações e os conceitos são assumidos pela sociedade e de que forma contribuem para as reflexões sobre o mundo? Como são construídas as impressões que os indivíduos têm acerca de temas como a homossexualidade? Tais perguntas podem ser respondidas com a participação da Teoria das Representações Sociais, de Serge Moscovici (1961), que sugere a existência de um pensamento social resultante das experiências, das crenças e das trocas de dados que integram o cotidiano. As representações sociais podem ser definidas como um conjunto de opiniões, comportamentos, atitudes, crenças e posicionamentos determinados pelos sujeitos, sua realidade e seus vínculos, estabelecidos com os indivíduos com os quais convivem. A respeito das representações sociais, Pavarino escreve: 
Para Moscovici o fenômeno das representações sociais é próprio das sociedades pensantes - thinking society - onde os acontecimentos ocorrem em ritmo acelerado, onde não há tempo suficiente para que as representações se tornem uma tradição, ou seja, das sociedades contemporâneas. Não se resumindo aos acontecimentos culturais ou políticos, este fenômeno constitui uma forma de pensamento social que inclui as informações, experiências, conhecimentos e modelos que, recebidos e transmitidos pelas tradições, pela educação e pela comunicação social, circulam na sociedade. (2003, p.5).

Os fenômenos sociais podem ser entendidos e estudados com maior precisão quando se leva em consideração a Teoria das Representações Sociais, que, segundo Scardua e Souza Filho (2006), parte da ideia de que os grupos e a sociedade compartilham conhecimento sobre a realidade em que estão insridos e os permite compreender de que maneira um fenômeno social pode ser entendido, explicado e difundido. Atuando como um elo entre conceitos e suas percepções, a representação social é uma ponte que une a cognição e as estruturas sociais.

Assim, segundo Pavarino (2003), podemos perceber que o cotidiano está permeado por explicações que vão além do conhecimento científico, o que nos permite perceber como as representações sociais podem explicar, por exemplo, o fato de ainda encontrarmos em nossa sociedade a permanência da crença em horóscopo e curandeiros, apesar de não haver comprovação científica para ambos.

Ao analisar as representações sociais, percebe-se que elas apresentam dois componentes: o consensual, isto é, o senso comum, no qual elas são elaboradas, onde os indivíduos constroem suas opiniões e posicionamentos sobre política, economia, ciências, meio ambiente, violência, racismo, exclusão social e outros tantos assuntos, e o concreto, também denominado reificado, que abarca o universo científico e o discurso acadêmico. Sobre este último, Pavarino declara: "O universo reificado, por outro lado, é o científico, onde há o certo e o errado, o verdadeiro e o falso, o autorizado e o não autorizado, o qualificado e o não qualificado." (2003, p. 8).

Sob esse aspecto, a homossexualidade assume grande importância no contexto das representações sociais, pois se trata de um tema complexo, que tem motivado discussões. Para Scardua e Souza Filho (2006), muitas questões se impõem aos pesquisadores envolvidos em estudos relativos à 
homossexualidade, já que há maneiras diferentes de se concebê-la, tanto no discurso acadêmico, quanto no senso comum.

A homossexualidade é forjada socialmente. Ideias, preconceitos, imagens e concepções são intercambiadas entre pessoas e as ajudam a discutir suas nuances. Neste sentido, Scardua e Souza Filho (2006) afirmam ser necessário ouvir grupos para poder compreender como eles lidam com a homossexualidade. Existe um conhecimento compartilhado socialmente sobre este tema, que possibilita práticas entre indivíduos e grupos.

Os autores consideram que a homossexualidade é construída socialmente e só pode ser analisada à luz de um contexto social e histórico dinâmico. Em relação à construção social da homossexualidade, pode-se recorrer à elaboração ou às transformações sofridas pelo conceito de identidade ao longo do tempo para melhor entendê-la. A identidade está em franca discussão, no centro de um debate sociológico. Segundo Hall (1992), a identidade tem sido amplamente discutida na teoria social, com o argumento de que as velhas identidades, que antes estabilizavam o mundo social, declinaram e fizeram surgir novas identidades e fragmentaram o indivíduo moderno, até então visto como unificado.

A fragmentação da identidade, influenciada por aspectos socioeconômicos, culturais, políticos, religiosos e ideológicos, coloca a sociedade diante de distintos posicionamentos diante da homossexualidade: há indivíduos ou grupos que a classificam como uma anormalidade, algo desviante, a despeito das evidências (inclusive científicas) que demonstram o contrário, e existem também aqueles que advogam a favor dos gays, defendendo suas causas, seus interesses.

Um tipo diferente de mudança estrutural está transformando as sociedades modernas no final do século XX. Isso está fragmentando as paisagens culturais de classe, gênero, sexualidade, etnia, raça e nacionalidade, que, no passado, nos tinham fornecido fortes localizações como indivíduos sociais. Estas transformações estão também mudando nossas identidades pessoais, abalando a ideia que temos de nós próprios como sujeitos integrados. Esta perda de um "sentido de si" estável é chamada, algumas vezes, de deslocamento ou descentração do sujeito. Esse duplo deslocamento - descentração dos indivíduos tanto de seu lugar no mundo social e cultural quanto de si mesmos - constitui uma 'crise de identidade' para o indivíduo. (HALL, 1992, p. 9). 
A noção de identidade fixa, estática, imutável, que fazia com que o indivíduo mantivesse sempre as mesmas opiniões e visões acerca do mundo e da vida, encontra-se em processo de redimensionamento. Segundo Hall (1992), o sujeito do Iluminismo, cujo "centro" consistia num núcleo interior e que permanecia o mesmo ao longo de toda a existência, já não vive mais. Tendo como base o sujeito sociológico, diz-se que cada pessoa ainda possui um núcleo central, o "eu real", mas esse "eu" é formado e transformado por meio do contato com o mundo exterior e as identidades que tal mundo coloca diante de cada um. "A identidade então costura (ou, para usar uma metáfora médica, 'sutura') o sujeito à estrutura". (HALL, 1992, p. 12).

Retomando a perspectiva de análise das representações sociais, pode-se dizer que uma das principais preocupações de Moscovici foi entender a maneira pela qual as sociedades lidam com o saber científico, cuja presença causava enorme impacto social. $\mathrm{O}$ autor desejava saber como a ciência interferia no discurso leigo. Entretanto, o estudo das representações sociais se prestou também para outro fim, como descrevem Scardua e Souza Filho:

[...] a noção de representações sociais acabou servindo também de base para a descrição e explicação de conhecimento social elaborado e difundido para lidar com assuntos, eventos, indivíduos e grupos, que não se ajustam aos padrões culturais dos grupos mais numerosos, ou seja, o que é considerado estranho, indefinido ou incontrolável, como a homossexualidade. (2006, p. 483).

Converter algo estranho ou considerado anormal em normal ou aceitável seria umas das incumbências das representações sociais. De acordo com Moscovici (1978), uma das funções das representações sociais seria a de gerar comportamentos e comunicações entre indivíduos, além de transformar algo não familiar em familiar. Nessa passagem ou conversão de não familiar em familiar, pode-se retomar a discussão sobre a formação da identidade e abordar o papel dos movimentos sociais, em especial o gay, na colocação da homossexualidade em posição de destaque no debate sobre as estruturas sociais.

"Cada movimento apelava para a identidade social de seus sustentadores. Assim, o feminismo apelava às mulheres, a política sexual aos gays e lésbicas, as lutas raciais aos negros, o movimento antibelicista aos pacifistas, e assim por diante." (HALL, 1992, p. 45). Os movimentos sociais entram na composição das representações sociais, tanto no que se denomina objetivação, quanto na ancoragem: 
Há dois processos principais, de acordo com Jodelet (1986), referentes à construção da representação social. São eles a objetivação e a ancoragem. O primeiro refere-se ao processo de transformação do objeto da representação em algo objetivo, ou seja, passa do abstrato para o concreto. Segundo Jodelet, este processo ocorre através das seguintes fases: (a) seleção e descontextualização, quando as informações relacionadas a um objeto de representação são escolhidas e utilizadas em função de critérios culturais e normativos dos grupos/ indivíduos; (b) formação de um "núcleo figurativo", quando se dá a reprodução de uma estrutura conceitual a partir de uma estrutura imaginante visível; e (c) a naturalização, quando ocorre a atribuição de qualidade da natureza aos elementos do núcleo figurativo, como se tivessem vida própria. Já a ancoragem, refere-se à inserção da representação e do seu objeto no social, ou seja, se refere à forma como um conhecimento se insere no pensamento pré-existente. Neste processo, ainda segundo Jodelet (1986), significação e utilidade são conferidas à representação social em relação ao seu objeto. Trata-se de produzir um conhecimento para os fins práticos de cada sujeito social, tais como influenciar, sobreviver, entre outros. (SCARDUA; SOUZA FILHO, 2006, p. 483).

As questões relativas à identidade sexual, à identidade de gênero e ao desejo têm sido apontadas como forma de contestação às rigorosas regras de convivência socioculturais existentes. Encaradas como uma construção social, são repetidas nas relações e nos discursos sociais como experiências complexas, permitindo considerar o debate em torno desta problemática.

Argumentos discriminatórios a homossexuais e a pessoas vivendo com o HIV, como se gays fossem o repositório natural da doença, podem ser identificados em vários períodos, entre eles, o da década de 1980, em que a AIDS causava medo, já que era uma enfermidade desconhecida e amplamente associada à homossexualidade:

O Governo da Grã-Bretanha ainda não sabe como, mas está estudando uma fórmula que torne ilegal a entrada no país de portadores do vírus da Aids. Já se sabe que em pelo menos uma ocasião isto ocorreu: um comissário de bordo da empresa americana Delta foi impedido de desembarcar no aeroporto de Londres. Na França, o Ministério da Saúde também busca um meio legal de adotar a medida, apesar dos protestos de médicos, psicoterapeutas e pesquisadores, que a consideram ineficiente. (O GLOBO, 1987, p. 30). 
O estigma que recai sobre homossexuais pode manifestar-se de várias maneiras: uma delas vincula a sexualidade à transmissão de doenças. Não só a AIDS, mas também a outras enfermidades, como sífilis e gonorréia. Isso pode ser observado na matéria acima e no trecho de outra reportagem de O Globo: "os médicos se preocupam também com a identificação da maior fonte de contaminação no Brasil e chegaram à conclusão de que os homens bissexuais estão servindo de ponte, levando a doença ao grupo de heterossexuais". (VILLELA, 1989, p. 15).

No texto jornalístico citado, a bissexualidade e a homossexualidade (ainda que indiretamente) aparecem como responsáveis pela chegada da AIDS ao universo de pessoas "normais": conforme Paula e Paula (2020), indivíduos cujo comportamento não é aceito pela sociedade tradicional, com conduta dita desviante, disseminavam um vírus contra o qual não se podia fazer frente. Via de regra, atribui-se aos homens homossexuais a prática sexual livre, a libertinagem, como relatam Simões e França:

De um ângulo, o desenvolvimento da área "moderna" dos Jardins e de seus pontos avançados parece apenas reforçar tendências detectadas desde os anos 70, para entronizar a imagem do homossexual moderno como consumidor sofisticado, hedonista e individualista - aos homens homossexuais em geral, independentemente do estilo ou poder aquisitivo, continua se associando uma intensa e variada prática sexual sem envolvimentos nem arrependimentos, em que pese toda a experiência recente da epidemia HIV - Aids. (2005, p. 329).

Estereótipos, no âmbito das representações sociais, colocam homossexuais com características socioeconômicas distintas dentro de um mesmo grupo: o da promiscuidade. Todos se relacionam na busca pelo sexo, não são capazes de manter relações duradouras e baseadas também no afeto. Não há envolvimento. É o que permeia essa representação social.

Nesta perspectiva de não aceitação das relações homoafetivas, visões negativas acerca da homossexualidade estão presentes também entre os próprios homossexuais. Há aqueles que não querem ser associados a lugares frequentados por outros homossexuais:

Mesmo hoje, o "gueto" (ou o "meio", como às vezes é referido) segue como alvo de repulsa por parte dos que, pelas razões mais diversas, não querem ser identificados com ele, mesmo que o frequentem. Por isso, também, a "defesa 
do gueto" continua a ser um tema candente e atual. Que os territórios reais e virtuais aqui tratados - por mais ampliados, diversificados e pluralistas - ainda sejam reconhecidos como "guetos" é um indicador da tensão recorrente entre os esforços de "pluralizar o universal", combatendo a segregação e a incomunicabilidade das diferenças, e a necessidade de manter espaços protegidos diante da intolerância que persiste sob múltiplas formas e procedências. (SIMÕES; FRANÇA, 2005, p. 333).

Neste sentido, não é incorreto afirmar que a despeito dos ganhos e avanços na discussão da homossexualidade e dos direitos civis, talvez ainda falte mais conquistas em termos de cidadania e da ocupação do espaço público, de maneira a garantir maior visibilidade e facilitar a negociação entre os diversos atores presentes no palco social.

\section{SOROFOBIA, PESSOAS VIVENDO COM HIV, AIDS E HOMOS- SEXUAIS}

A Sorofobia, nome dado à discriminação sofrida por viver com HIV, consiste na invisibilidade e aversão que as pessoas vivendo com HIV sofrem na sociedade, e remonta ao aparecimento de uma doença, a AIDS. A infecção sexualmente transmissível, quando surgiu, despertou medo e intensificou preconceitos preexistentes: contra homossexuais, usuários de drogas, prostitutas.

No HIV, a pessoa é discriminada antes de ser soropositiva. Ou seja, quando você é migrante, você é discriminado; quando você é usuário de drogas, você é discriminado; quando você é homossexual, você é discriminado. Agora, são essas pessoas que, principalmente, se encontram com HIV (...). Os outros doentes tomam consciência das injustiças, uma vez que eles se tornam doentes, enquanto um homossexual faz já a experiência da homofobia, antes de ser soropositivo.” (SPIRE, 2011, p. 157).

Pessoas vivendo com HIV pertencem a uma categoria de indivíduos marginalizados, sobre os quais recaem estigmas e que são tratados como indignos.

AIDS chegou ao Brasil com caráter de "peste anunciada", vinculada, naquele momento, a grupos marginalizados, como homossexuais, usuários de drogas injetáveis, prostitutas, michês e travestis, agrupados na categoria de "grupo de risco". Estes formavam, nesse sentido, "espécies”, no sentido empregado por 
Foucault" ao discutir a construção da homossexualidade enquanto fenômeno clínico. Essa nova "espécie" foi aglutinada na categoria clínica de "aidético". São estes grupos que a nossa sociedade sempre caracteriza ou associa a este tipo de doença, porque são pessoas marginalizadas pela própria sociedade devido a modo de vida que essas pessoas levam. (PELUCIO, 2007, p. 127).

Para pesquisadores como o infectologista Ricardo Vasconcelos (2020), enquanto a ciência se dedicou ao entendimento do HIV, sua transmissão e como evitá-la, houve uma multiplicação de notícias falsas, criadas a partir de informações. E muitas dessas mentiras atrapalharam enormemente o trabalho dos médicos e das autoridades de saúde, e algumas delas até hoje encontram abrigo no senso comum, perpetuando a discriminação. O infectologista dá exemplos disso: "Em 2020 eu ainda ouço no consultório perguntas absurdas como 'Melhor separar os talheres e a roupa de banho?', 'Posso usar o mesmo canudo?' ou 'Estou preocupada pois eu o beijei na boca'. (VASCONCELOS, 2020, sem página). E ele crescenta: “Ou, o que é ainda pior vejo profissionais da saúde argumentando que HIV é doença de homens gays, portanto heterossexuais não apresentam riscos de se infectarem". (VASCONCELOS, 2020, sem página).

Falsas informações por vezes ganham repercussão inclusive nas falas de profissionais da comunicação, como no caso envolvendo o jornalista Leandro Narloch, que se manifestou de maneira homofóbica em um programa da CNN, emissora de televisão por assinatura:

De acordo com o Fefito em sua coluna no TV e Famosos do UOL, o comentarista Leandro Narloch foi demitido da CNN Brasil na tarde desta sexta-feira, dia 10 de julho. O contrato foi rescindido unilateralmente. Os comentários de Narloch geraram grande repercussão negativa no último dia 8 de julho ao dizer que os homens gays "têm uma chance muito maior de ter AIDS", contrariando os dados do Ministério da Saúde que aponta que 57,74\% dos brasileiros que contraem HIV através do sexo são heteros. (MILLER, 2020, sem página).

O infectologista Ricardo Vasconcelos aponta que o preconceito contra homossexuais e pessoas vivendo com HIV advém de incorreta interpretação de dados epidemiológicos. Esse é um erro bastante comum entre aqueles que não estudam o assunto. "Não compreendendo toda a complexidade da dinâmica de disseminação desse vírus no Brasil e no mundo, acabam ficando 
com a análise superficial e preconceituosa dos números." (VASCONCELOS, 2019, sem página).

Vasconcelos (2020) explica que a epidemia de HIV no Brasil tem um padrão dito concentrado, o que significa que, na população geral, há uma prevalência baixa da infecção, em torno de $0,4 \%$, enquanto em alguns subgrupos específicos, esse percentual sobe para valores muito mais altos. Entre homens gays e bissexuais, por exemplo, a prevalência de HIV subiu de 12 para 18\% entre 2009 e 2016, e entre as mulheres trans e travestis ultrapassa os 30\%.

A análise rasa e equivocada que frequentemente é feita desses números é a de culpabilização das populações que apresentam as altas prevalências, quando, na verdade, todo o universo acadêmico e científico mundial que estuda HIV entende que elas são as vítimas de uma epidemia que é mediada por fenômenos sociais. (VASCONCELOS, 2019, sem página).

Homens gays e também bissexuais, assim como mulheres trans e travestis, são mais vulneráveis à infecção pelo HIV por conta do preconceito e da marginalização, não conseguindo acesso a todas as formas de prevenção disponíveis. "O que têm de diferente as pessoas que vivem saudáveis com HIV e as que morrem de Aids? A discriminação e a exclusão social a que são submetidos". (VASCONCELOS, 2019, sem página).

[...] Quer um exemplo? A população negra de São Paulo apresenta mortalidade em decorrência da Aids maior do que a branca. Se a infecção por HIV não causa um quadro clínico mais grave entre as pessoas de cor preta e nem o tratamento antirretroviral funciona pior para eles, esse dado apenas escancara a forma como o racismo influencia na desigualdade social e de acesso à saúde no Brasil. Mais do que isso, se um subgrupo é historicamente mais impactado por uma epidemia, a ausência de uma abordagem individualizada para ele que trate da educação, prevenção, testagem e tratamento dessa doença, por parte das autoridades de saúde pública, é por si só um fator impulsionador do crescimento dos seus casos.

A homofobia acaba atuando como uma espécie de catalisadora da epidemia de HIV/AIDS no Brasil. 


\section{CONSIDERACÕES FINAIS}

Viver com HIV é diferente de ter AIDS. Essa confusão até certo ponto compreensível, ainda ocorre em 2021, e precisa ser esclarecida: há quem viva com o Vírus da Imunodeficiência Humana sem desenvolver a Síndrome da Imunodeficiência Adquirida. Além disso, é necessário reafirmar que homossexuais não são repositórios naturais do vírus ou da infecção sexualmente transmissível. É preciso lançar informação e conhecimento científico sobre tais questões para que indivíduos ou certos grupos populacionais não sejam julgados e pré-julgados à luz de códigos morais, religiosos ou de qualquer outra natureza, que não contenham nenhum substrato científico e que sirvam apenas para espalhar preconceito e produzir segregação.

A AIDS e o HIV podem estar presentes em corpos e organismos de diferentes etnias e culturas, de todas as orientações sexuais, sem distinção. Se em determinados segmentos da população é maior a prevalência da infecção pelo HIV, é preciso compreender que as justificativas para tal fato vão além do modelo biomédico tradicional e que seus alicerces são formados por elementos sociais, econômicos, políticos e humanos.

\section{REFERÊNCIAS BIBLIOGRÁFICAS}

CIASCA, Saulo Vito; POUGET, Frederic. Aspectos históricos da sexualidade humana e desafios para a despatologização. In: CIASCA, Saulo Vito; HERCOWITZ, Andrea; Lopes Junior, Ademir. Saúde LGBTQIA+: práticas de cuidado transdisciplinar. Santana de Parnaiba: Manole, 2021, p. 18-27.

HALL, Stuart. "A identidade em questão" In: Rio de Janeiro: DP\&A editora, 1992, p. 7-22. A identidade cultural na pós-modernidade.

MOSCOVICI, Serge. A Representação social da psicanálise. Rio de Janeiro: Zahar, 1978.

PAULA, Thayane Fraga de; PAULA, Thaís Fraga de. A Construção Social da AIDS e as Repercussões na Prática dos Profissionais de Saúde. Braz. J. Hea. Rev., Curitiba, n. 4, v. 3, p. 9844-985,7 jul./aug. 2020. Disponível em: https://www.brazilianjournals.com/index.php/BJHR/article/view/14409/11976. Acesso em: 05 maio 2021.

PAVARINO, Rosana Nantes. Teoria das representações sociais: pertinência para as pesquisas em comunicação de massa. In: XXVI Congresso anual em ci6encia da comunicação, 26., 2003, Belo Horizonte. Anais... Belo Horizonte: Congresso Anual em Ciência da Comunicação, 2003, p. 01-15. Disponível em:< http://www.academia.edu/1939362/Teoria_das_Representa $\%$ C3\%A7\%C3\%B5es_Sociais_Pertin $\%$ C3\%AAncia_para_as_pesquisas_em_comunica\%C3\%A7\%C3\%B5es_de_massa >. Acesso em: 02 maio 2021.

PELUCIO, Larissa. Ativismo soropositivo: a politização da AIDS. Ilha - Revista de Antropologia, n. 1, 2, v. 9, p. 119-141, 2007.

SCARDUA, Anderson; SOUZA FILHO, Edson Alves de. O Debate sobre a homossexualidade mediado por representações sociais: perspectivas homossexuais e heterossexuais. Psicologia: Reflexão e Crítica, Porto Alegre, v. 19, n. 3, p. 482-490, 2006. Disponível em:< -http://www.scielo.br/scielo. php?pid=S0102-79722006000300017\&script=sci_abstract\&tlng=pt $>$. Acesso em: 01 maio 2021. 
SIMÕES, Júlio Assis; FRANÇA, Isadora Lins. Do "gueto" ao mercado. In: GREEN, James N.; TRINDADE, Ronaldo. (Org). Homossexualismo em São Paulo e outros escritos. São Paulo: UNESP, 2005. cap. 5, p. 309-333.

SPIRE, Bruno. Entretien avec. Cahiers Philosophiques, n. 125, v. 2, p. 153-171, 2011.

\section{Fontes documentais}

Medo da Aids põe países europeus em alerta total. O Globo, Rio de janeiro, 22 de fevereiro de 1987. Caderno O Mundo, p. 30. Disponível em: $<$ http://acervo.oglobo.globo.com/busca/?tipoConteudo=pagina\&ordenacaoData $=$ relevancia\&allwords $=$ gays + e + promiscuidade \&anyword $=\&$ noword $=\&$ exactword $=\&-$ decadaSelecionada $=1980 \&$ anoSelecionado $=1987>$. Acesso em: 25 mar. 2018.

MILLER, Victor. CNN Brasil demite comentarista Leandro Narloch após discurso homofóbico. Disponível em: https://gay.blog.br/gay/cnn-brasil-demite-comentarista-leandro-narloch-apos-discurso-homofobico/. Acesso em: 02 maio 2021.

VASCONCELOS, Rico. Aprendizados da epidemia de HIV que são úteis para a de coronavírus. Disponível em: https://ricovasconcelos.blogosfera.uol.com.br/2020/02/28/aprendizados-da-epidemia-de-hiv-que-sao-uteis-para-a-de-coronavirus/. Acesso em: 02 maio 2021.

VASCONCELOS, Rico. Entenda por que é um erro associar o aumento do HIV à homossexualidade. Disponível em: https://ricovasconcelos.blogosfera.uol.com.br/2019/09/13/entenda-por-que-e-um-erro-associar-o-aumento-do-hiv-a-homossexualidade/. Acesso em: 02 maio 2021.

VILLELA, Heloisa. Aids: estudo aponta vírus africano no Brasil. O Globo, Rio de Janeiro, 13 abril de 1989. Caderno O Mundo, p. 15. Disponível em:< http://acervo.oglobo.globo.com/busca/?tipoConteu$\mathrm{do}=$ pagina\&ordenacaoData $=$ relevancia\&allwords $=$ hiv $+\% 2 \mathrm{~B}+$ aids\&anyword $=\&$ noword $=\&$ exactword $=\&-$ decadaSelecionada $=1980 \&$ anoSelecionado $=1989>$. Acesso em: 05 maio 2018. 